\title{
Erratum: Pediatric Neuroradiology: Clinical Practice Essentials
}

\author{
Eugen Boltshauser ${ }^{1}$ \\ ${ }^{1}$ Department of Pediatric Neurology, University Children's Hospital, \\ Zurich, Switzerland \\ Address for correspondence Prof. Emeritus Eugen Boltshauser, MD, \\ Department of Pediatric Neurology, University Children's Hospital, \\ Steinwiesstrasse 75, 8032 Zurich, Switzerland \\ Neuropediatrics 2017;48:e1. \\ (e-mail: eugen.boltshauser@bluewin.ch).
}

ERRATUM
It has been brought to the Publisher's attention that in the Book Review published online in Neuropediatrics on June 1, 2017 (DOI: 10.1055/s-0037-1603533), the author's name of the book titled "Pediatric Neuroradiology: Clinical Practice Essentials" was misspelt as "Asim F. Choudri" in the heading and text of the book review. The correct listing of the author's name is Asim F. Choudhri. 